\title{
Philadelphia Chromosome Positive
}

National Cancer Institute

\section{Source}

National Cancer Institute. Philadelphia Chromosome Positive. NCI Thesaurus. Code C128843.

Indicates that the Philadelphia chromosome abnormality, $t(9 ; 22)(q 34 ; q 11)$, has been detected in a sample. 